\title{
Study on Relevance of Cognitive Context and Business English Writing Qinying Wang ${ }^{1}$ \\ ${ }^{1}$ Jiangxi College of Foreign Studies, Nanchang, Jiangxi, 330099 59624917@163.com
}

\author{
Keywords: Cognitive Context, Business English Writing, Context Control
}

\begin{abstract}
Globalization of the world economic development, the need for business people to study English writing. "Business Writing" is China's reform and opening up, with the development of China's foreign economic and trade and the emergence of a new discipline. From the perspective of cooperative principle, politeness principle and the principle of relevance and economic principles to analyze the cognitive context of the principle of business English writing, we discuss the Business English Writing contingent word sentences, text and context, language features of acronyms used.
\end{abstract}

\section{Introduction}

Context is when verbal communication environment. From the linguistic point of view of human cognition to produce and understand language are inseparable interaction between people and all other external factors which is the cognitive experience. Cognitive Context statement through bilateral exchanges continue to live in the Context of the upper and lower contact, exchanges of tone, and body movements, exchange of the occasion, many aspects of status of both parties, ethnic and cultural differences to judge, identification, reasoning, then in accordance with the reasoning in the existing tone, body language and other context be amended in order to achieve better complement the exchange effect.

Business English writing vocabulary occur in specific business activities involved certain syntactic format has its own peculiarities. Compared with the public English Kai contained more professional terms, some words have been given a special meaning. Business English Writing cases involving business consulting, consulting reply to the letter, the sale of a complaint claims for refuse unreasonable requirements, customer invitations, festival, application letter, the person or company letters of recommendation or notice of the meeting report records and so on.

\section{The Basic Theory of Cognitive Context and Business English Writing}

From the perspective of cognitive linguistics, context should be having cognitive, because the requirement to produce and understand language interaction with the outside world, namely cognitive experience. Relying solely on the traditional context view (ie the context of this article, the context, or the interaction between speaker and hearer's) is not enough to complete the transmission of information. That is the analysis of the context of the time we can combine the interactive experience of man and the environment, and analyzed on the basis of the concept of Wikipedia. Discourse plays an important role in understanding the cognitive context of the hearer posed a series of assumptions, because the hearer needs to handle the new hypothesis by the speaker of the discourse established by a series of contextual assumptions and assumptions from old and new relationship reveals a new hypothesis contextual effect, to derive the meaning of discourse. Control means in the context of the communication process, communication both sides in accordance with communicative situation (including social situations, topics, communication identity, status, cognitive level, communication both sides clear information, the two sides of understanding and other factors) for the current session speech conduct select, control, finally achieved the best effect in the process of communication. Context control purpose is to achieve the optimal allocation of verbal information, namely on the one hand makes the most concise speech, on the other hand to achieve the best communication results. 
In the communication process, the context is one in a dynamic state, to grasp the context requires communication both sides were constantly on the existing context reasoning, judgment, identification, characterization in the session. Then again follow the reasoning of the current context for continuous correction, supplement. In a clear purpose, topic specific communicative behavior, information transmission in conservation status, if the two sides are more communicative context of mutual next higher level of understanding, then the information will be passed verbal communication less. Conversely, if the two sides due to the communicative and cognitive disparity between the level of familiarity with each other and cause less clear context, then, successful communication requires language table will increase the amount of information obtained. Context control mode session is tantamount to restricting speech information in a market economy the law of value curve. Conservation is the ideal state and the imbalance is a common occurrence.

Business English Writing Since the establishment in the early 1980s has gone from a purely business English teaching content and practice and gradually expand to wider areas of economic and trade development, the teaching content and teaching methods are being perfected, it has formed a complete set more scientific and complete teaching system. Over the past decade, business English professional trained a large number of foreign trade English professionals for the development of foreign economic relations and trade made a great contribution to our country. Business English Writing based on economic life in order to reflect the object to language as a means of expression in articles for the dissemination of information carrier, in order to promote economic development due to its goal of social practice. It is the economic activity and assistant economic work, economic workers and other relevant personnel must master the tools and weapons. Business English Writing including inquiry and request, response letter, complaints and claims, claims and refused letter, sales letters, invitations and thank you note, a letter of apology and congratulations to inform and announcements, memos and meeting notes, resume, application letter, letters of recommendation, a letter of intent, reporting questionnaire and business documents.

To comprehensively improve the business English writing skills and communication skills, the need to use the latest research results at home and abroad for business communication, starting from the principles of communication, highlighting the characteristics of business writing, emphasizing clear and complete, clear and correct writing style and principles.

\section{Business English Writing Linguistics}

Seven Principles of Business English Writing using a pragmatic principle embodied. Cooperative principle, politeness principle and the principle of relevance are three important principles to guide the session on pragmatics. They are from the American linguist Grice, the famous British scholar Leech, French psychologist Sperber and British pragmatic scientist wilson proposed a specific scenario session and pragmatic research played an important role.

Grice's cooperative principle and conversational implicature in verbal communication describes the people for cooperation in compliance and violations, as well as the derivation of meaning conversation, but did not explain it if it wants to abide by the principles of cooperation, why should deliberately violate the principles of cooperation; Leech think people violate Cooperative Principle is a courtesy, on this basis, he proposed the politeness, the purpose is to compensate for the lack of cooperation principles; and Sperber and wilson made from a cognitive perspective association principles, to further improve the cooperation principle.

Business English letters are inseparable from writing naturally Pragmatic Principles guidance. Cognitive context principle used in business English writing, in view of the principle of cognitive context own limitations and lack of reference to the principle of business English writing, put forward the principles of cognitive context category Business English applications. Only a good grasp of the principles of cognitive context of the scope of application, in order to play its role in guiding a greater extent, so that the principle of business English writing more reasonable and perfect. From the point of view of language application, with culture does not mean to have a good knowledge of business English writing ability. First of all, high-rise multi-cultural knowledge of teaching culture as its main content, ignoring the direct role of culture in people's daily 
communication and cultural factors specific to reflect in Communication, Culture and Communication will be separated, although learners have a lot of cultural knowledge but it can not be applied in actual business English writing.

\section{The Relevance of Cognitive Context and Business English Writing}

Business English is a communicative act, in the framework of relevance theory, communicative behavior is a cognitive behavioral explicit reasoning, it has a strong cognitive characteristics. Lenovo is an important type of imagination, it is implemented in the whole process of creativity in business English, business English and creative adhesive. Commonly used in business English and creative way in nearly Lenovo, Lenovo and contrast relations association four. Rational use of the psychological phenomenon Lenovo Business English creative audience can cause concern, affecting mood and behavior of the audience, so that the effect is more direct business English, more pronounced. From the perspective of cognitive context associated with the use of departure to explore the association of ideas in business English it is necessary.

Relevance theory is that the degree of association depends on the context of discourse effects and processing effort, contextual effects associated with proportional inversely associated with processing capability. The authors deal with trying to understand the cognitive locale consumed mental association is stronger, more direct words, the consumption of brain cognitive smaller, smaller, then bring to the subject of cognitive load; association weaker, more implicit discourse, the greater the consumption of brain power, the greater the recipient's cognitive load. Communication Speaker decrease use of cognitive load on the performance for the use of a communication strategy. Relevance Theory and the basic language of communication as communication both sides shared cognitive environment that discourse is basically a piece of nature, pragmatic person in the course of the discourse within the meaning of the words must also be clear instructions, excluding the lexical ambiguity, The fragments of discourse substantial propositions form a complete derivation process, supported by the reasoning produce cognitive context. Pragmatic reasoning is based on the interpretation of the rules of procedure on the basis of the non-trivial nature associated obtain communicative, pragmatic inference is comprehensive in nature, the interpretation of the nature of the analysis rule operational errors are usually the result of a misunderstanding of the premise, and mistake the most comprehensive rule action is The null hypothesis of lack of exploitation. Business English Writing and its implementation and use of politeness strategies, Business English Writing reflect polite various forms of language and the use of different types of business letters in English law in politeness strategies.

In the theoretical framework of Brown and Levinson conducted a study on the Business English Writing politeness strategies. From the word, tense, voice and syntactic language point of view, analyzing language means four politeness strategies and form of Business English Writing, focuses on the most frequently used positive politeness strategy and negative politeness strategies. In Leech verbal behavior classification model is based on business letters in English class letters into cooperation, harmony class letters, letters and conflictive competition class letter, and to explore positive and negative politeness strategies in four categories of the distribution of the letter. Of the data collected for statistical chi-square test, draw four types of correspondence in the use of positive and negative strategy is different nature. Class Mail positive cooperation strategies and negative strategies appear less frequency, harmony class letters appear at frequencies above negative active policy strategy, negative policy competition class letters above the active strategy, conflict class letters is much higher than the frequency of occurrence of negative policy active strategy proportion is the highest.

\section{Conclusion}

Quoted on language issues, many scholars have done related descriptive study, particularly reflected in the grammatical form of the conversion terms, but see little in their interpretative aspect. Verbal communication is essentially a cognitive process, but the language quoted in the cognitive 
aspects related phenomena has been neglected. Cognitive pragmatic perspective on business English Writing language report described explanation. Business English Writing among the definition and delimitation, as well as related data analysis based on language report, written in the language quoted stylistic use also has some of its own characteristics. Information sources of information and relayed the information relayed language, relayed signs and relayed the information relayed by the attitude of the described system. Information can be relayed through a variety of different forms to others, relayed different forms by different communicative purposes of the decision, that is relayed through relayed want to achieve what purpose. Because language report is the result of linguistic factors and non-linguistic factors working together, they are only in the framework of the theory of cognitive language of business English writing knowledge of the specific application in order to get a reasonable explanation available.

\section{References}

[1] Lin Tianhu. Development of Business English Subjects. Xiamen University (Philosophy And Social Sciences), 2001, (04).

[2] Luo Mingli. Business English Writing of Pragmatic Features. Market Modernization, 2007, (25).

[3] Zhou Yan. Face Cognitive Style Relayed By Sign Language Analysis. China Excellent Theses Database (Master), 2005, (02).

[4] Lu Dan. Business Email Genre Analysis. China Excellent Theses Database (Master), 2006, (11). 